\title{
Sustainable development of the steel plate hot rolling technology due to energy-power process parameters justification
}

\author{
Viktoriya Chubenko*, Alla Khinotskaya, Tatiana Yarosh, and Levan Saithareiev \\ Kryvyi Rih National University, Ferrous metals metallurgy \& foundry Department, Ukraine
}

\begin{abstract}
In order to ensure sustainable development of rolling production, technological processes were investigated using computer simulation, which allows us to examine a large amount of information regarding modes of reduction and energy consumption of metal treatment under pressure in order to determine rational values. Simulation of hot rolling process using DEFORM-3D software was performed to investigate energy parameters of treatment and to determine rational reduction modes. During investigation, objects were located in space, exact positioning of casting rollers respectively to workpiece was performed, and rheological model of deformable material was specified, where rigid-plastic environment was adopted. Mechanical properties of workpiece material were determined, low carbon steel was selected as material, reduction between casting rollers was specified, and friction coefficient between workpiece and rollers, which is equal to 0.3 ; contact interaction between casting rollers and workpiece was specified, hot rolling temperature was set to $1000^{\circ} \mathrm{C}$. Finite element model of treated material was developed, displacement in deformation zone during hot rolling and vector field of metal movement were determined. Changes in force during treatment, deformation stress during rolling were determined. Changes of rolling force in deformation zone in course of time were determined. Distribution of active stress in deformation zone was investigated. Investigations allowed us to determine energy consumption of rolling process depending on reduction modes, which provided rational treatment modes.
\end{abstract}

\section{Introduction}

In recent years, scientists of the Ferrous metals metallurgy and foundry Department of Kryvyi Rih National University have studied such important and relevant areas: the impact of the electric field on the steel and cast iron structure during the pouring of the alloy into the mold: the study of processes in the deformation zones during the longitudinal rolling of steel billets.

Sustainable development of steelmaking production is impossible without detailed research and improvement of technological processes of rolling, which require high energy consumption. Recently, active development of informational technologies has made possible their widespread usage in development of metal treatment under pressure processes, which allows to solve problem of increasing of rolling production efficiency and ensure production of competitive products with required quality and with minimal energy consumption. Task to improve rolling technology using rational reduction modes, which provide required quality of products with minimum energy consumption is relevant. For this purpose, it is necessary to carry out research of metal treatment using DEFORM 3D computer software, which significantly speeds up treatment process improvement.

\section{Literature review and problem definition}

Development of technological processes of metal treatment under pressure processes to ensure sustainable development of industry and society requires solving of large number of complex problems. Main purpose of development and improving of rolling technologies is to identify regularities of process, significant factors and parameters that affect its quality, to evaluate possible effect of reduction parameters to operational properties of produced products, to energy consumption during production $[1,2]$. During rolling process, deformation zone is formed, which in is given much attention in theory of metal treatment under pressure because complex deformation processes take place in it, which further affect product quality and energy consumption of process. Investigations have shown that complex stress-strained state $[3,4]$ appears in deformation zone, which shall be taken into account during designing and improvement of technological processes, which is very difficult to investigate in manufacturing environment. During investigation of reduction processes using computer program, obtained data allowed us to develop informational field of technological processes of rolling, and thus provides ability to control both process and

\footnotetext{
*orresponding author: victoria 4@,rambler.ru
} 
properties of products. Computer simulation provides opportunity to obtain large amount of information, to conduct comprehensive investigation of rolling process, to determine its features, to consider and to compare large number of alternative technological processes. Currently, analytical energy method of power balance and finite elements analysis have been acquired to investigate bulk deformation processes during metal treatment under pressure. A lot of investigations were executed regarding defect formation problem during pressing using finite elements analysis $[5,6]$, but it shall be noted that hot rolling process of thick sheets is not investigated in this work. Currently, promising results are given by simulation modeling of bulk deformation processes using finite elements analysis [7], which is most common numerical method for solving technological tasks.

Computer software DEFORM 3D, which is designed to analyze complex three-dimensional processes of plastic deformation of metal while its reduction, has great potential in this respect. This program is finite element simulation system $[1,8]$ and one of leading design-grid methods that can be finally adapted to plastic deformation tasks solving. Simulation of rolling processes using DEFORM 3D has developed more rational technologies with significantly reduced time for their design [8]. Software [9, 10] was used for research of sheets hot rolling for analysis of three-dimensional metal flow during treatment, nature of metal forming was predicted, microstructure of products was obtained, deformation force was minimized, number of transformations was optimized, but energy consumption for process was not determined.

Therefore, there is reason to believe that insufficient attention is paid to distribution of rolling force and energy consumption for process during hot rolling simulating of thick sheets using DEFORM 3D.

\section{Purpose and tasks of research}

Purpose of this work is to investigate energypower parameters of hot-rolling process of thick sheets, using computer software DEFORM 3D for simulation, which will provide evaluation of rational treatment modes.

To achieve this goal, following tasks were set: - to analyze possibilities of using finite elements analysis for studying processes of metal treatment under pressure; - to develop model of hot rolling to study effect of rolling force on physical and mechanical characteristics of treated material;

- to determine energy consumption and rational reduction modes during process of hot rolling of thick sheets.

\section{Data and methods}

\subsection{Initial data for investigation of hot rolling of thick sheets}

Technology of thick strips production by hot rolling was used to determine rational technological parameters that will ensure sustainable development of industry. Initial data for simulation [11]: dimensions of initial billet height $h_{0}$ varied from 300 to $500 \mathrm{~mm}$; width $b_{0}$ remained constant and equaled $1000 \mathrm{~mm}$; length $l_{0}=1000 \mathrm{~mm} ; \Delta h$ of their reduction varied from 30 to $100 \mathrm{~mm}$; initial rolling speed $v_{0}$ varied from 3 to $10 \mathrm{~m} / \mathrm{s}$; radius of rollers $\mathrm{RB}=$ 400. Rolling temperature was $1000^{\circ} \mathrm{C}$. Low carbon steel was used as treated material.

\subsection{Methodology of investigation of energypower parameters of thick sheets hot rolling}

Model of hot rolling of thick sheets using computer software DEFORM 3D was built to determine rational reduction modes.

During simulation Perzyna's model was used [10]:

$$
\dot{e}=\gamma(\dot{\varepsilon} / S-1)^{m},
$$

where $\gamma$ - fluidity; $\dot{\varepsilon}$ - effective stress; $S$ - flow stress; $m-$ material parameter; $\bar{e}-$ effective strain rate.

In this method creep will not occur until effective stress exceeds the yield strength of material. If effective stress is less than the flow stress, the resulting strain rate is zero.

Yield strength of material was set according to energy law [10]:

$$
\sigma=\varepsilon^{n} \cdot u^{m}+y,
$$

where $\sigma$ is effective stress of plastic material flow, $\varepsilon$ is material deformation, $u$ is material deformation speed; $n$ is deformation degree indicator, $m$ is indicator of deformation degree speed, and $y$ is material constant.

Deformation process was studied at the beginning of rolling process: with help of computer program, objects were placed in space, distance between rollers was determined taking into account dimensions of workpiece and reduction value (Fig. 1), and rheological model of deformable material was identified, where rigid-plastic environment was adopted. While simulation, flexible model was used for workpiece, and rigid material model was selected for rollers. Behavior of workpiece material was described using diagram "Stress-Strain". Mechanical properties of workpiece material were determined, low carbon steel was selected as material, reduction between rollers was specified, and coefficient of friction between workpiece and rollers is equal to 0.3 ; contact interaction between roller and workpiece was specified, hot rolling temperature was set to $1000^{\circ} \mathrm{C}$, deformation speed, identified at the beginning of treatment, was $3 \mathrm{~mm} / \mathrm{s}$.

Deformation process was divided by 90 steps.

Number of steps was determined from formulas [9, 10]:

$$
n=x /(v \Delta t)
$$

where $n$ is number of steps, $x$ is summary movement of main roller, $v$ - main roller speed, $\Delta t$ is time increment for one step.

In order to divide workpiece into finite elements, grid was generated where 80,000 elements were specified (Fig. 2). Automatic grid generation mode was used during investigation. 


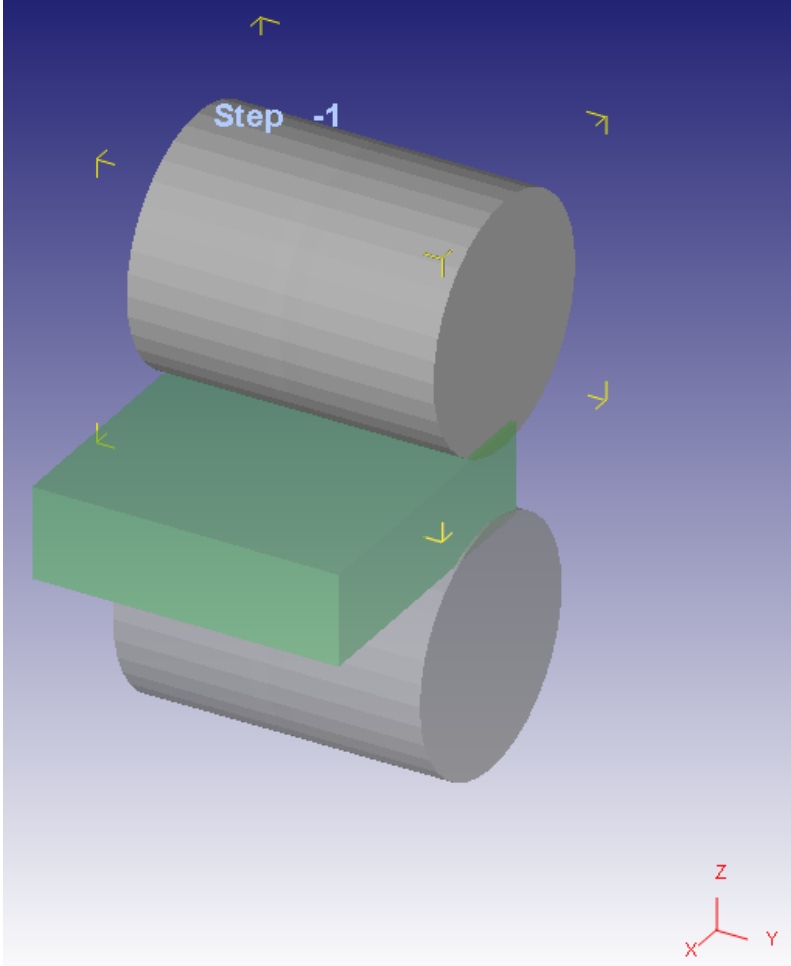

Fig. 1. Scheme of rollers and treated material location.

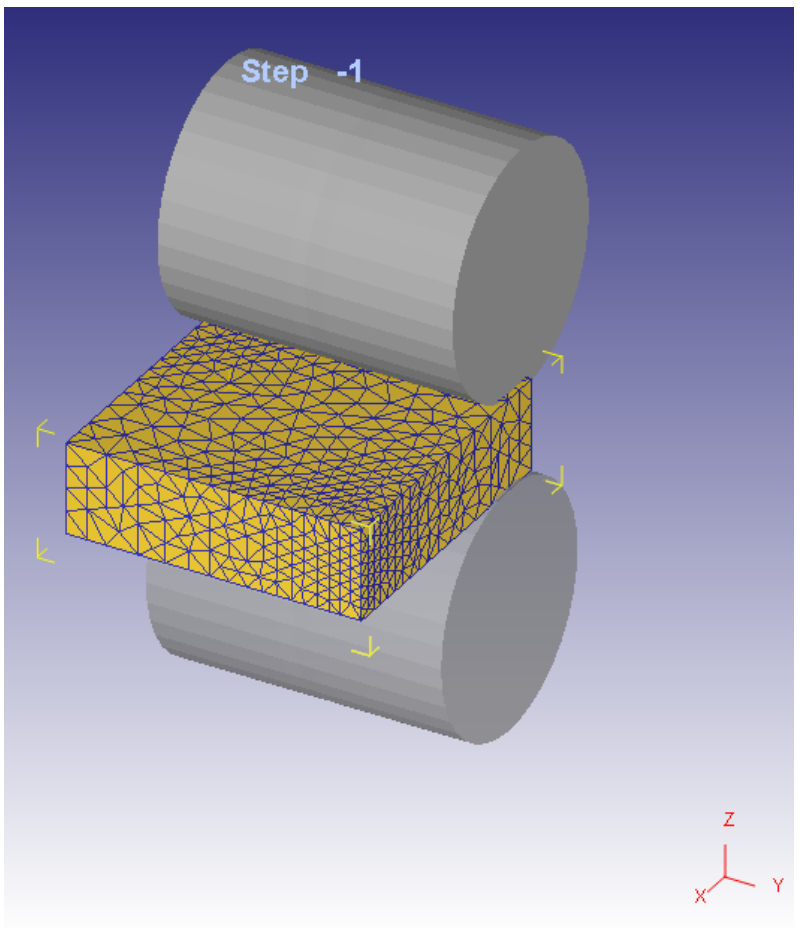

Fig. 2. Finite element model of treated material.

Scheme (Fig. 2) shows that during simulation process, workpiece having $1.37 \times 103$ points and 5.62×103 elements was obtained.

For exact location of objects, mutual positioning of rollers and workpiece was performed, as shown in Fig. 3, $a$ and $b$, where continuous interaction of rollers and workpiece side and back is observed.

Material of treated workpiece was determined from computer software library. AISI-1015_(20-1200C) carbon steel material was used for investigation. The properties of the material are learned in many ways. Material is easy to deform. The material has elastic and plastic properties.

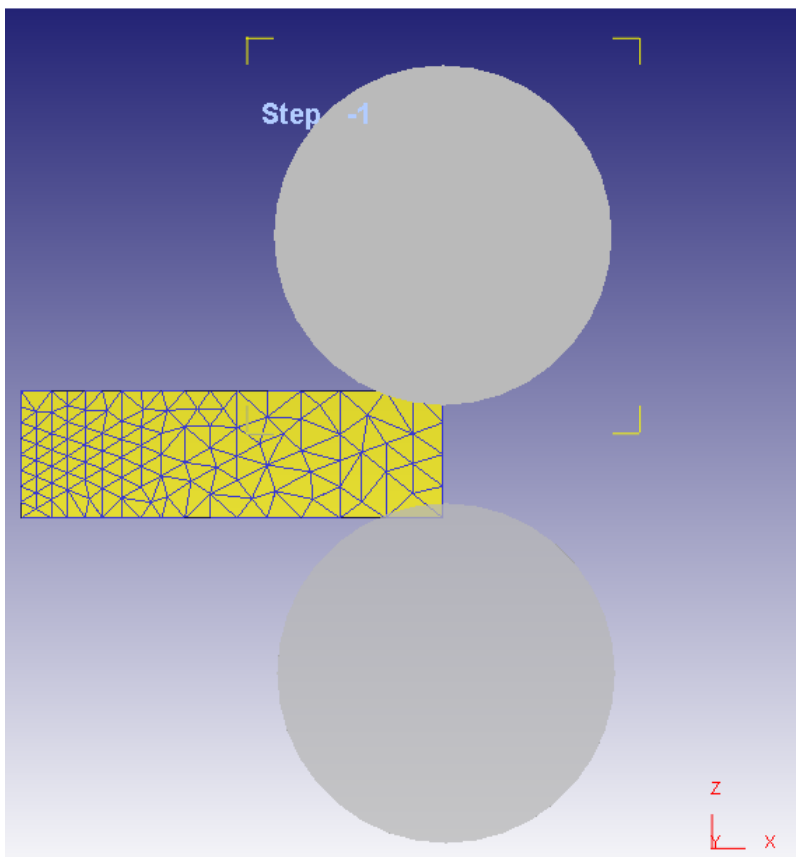

$a$

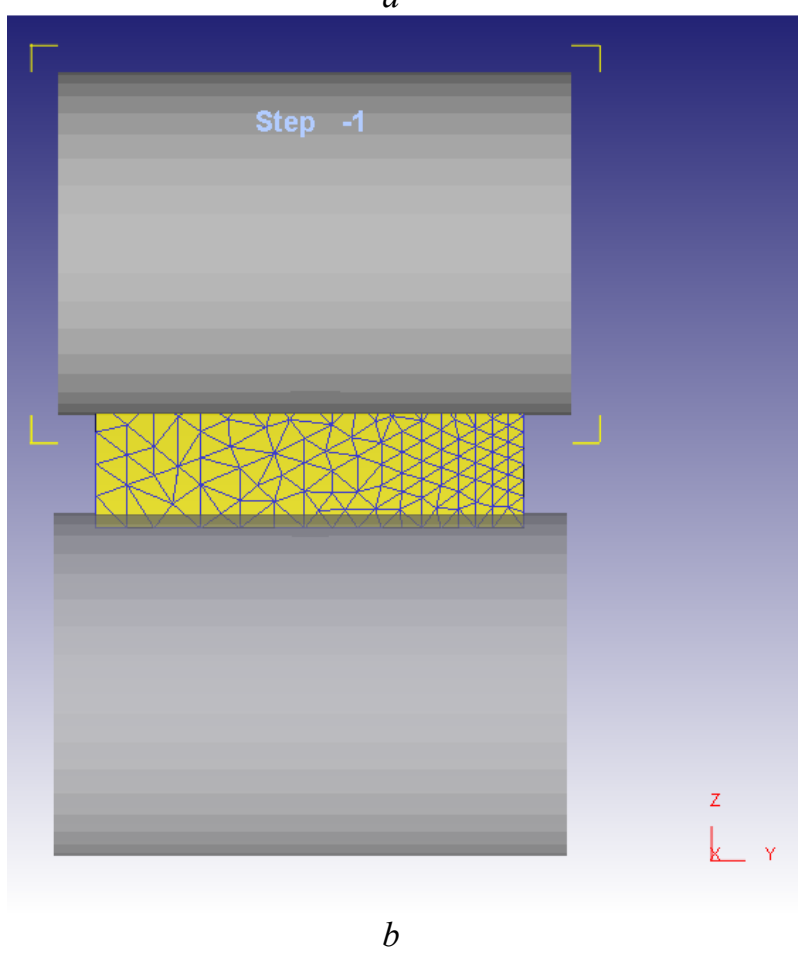

Fig. 3. Positioning of objects: a) side view; b) back view.

Elastic properties of material were determined (Young's modulus and Poisson's ratio), which equal to 0.3 and $1.5 \cdot 10^{5}$ accordingly, which are constant values. Diagram "Flow Stress-Strain" is presented in Fig. 4, which shows that if strain during reduction increases, flow stress increases as well.

Parameter "Strain" shows degree of workpiece relative reduction, which is determined according to 
formula [11]:

$$
\varepsilon=\Delta h / h_{0},
$$

where $\Delta h$ is absolute reduction,

$$
\Delta h=h_{0}-h_{1}
$$

where $h_{0}, h_{1}-$ initial and final thickness of strip accordingly.

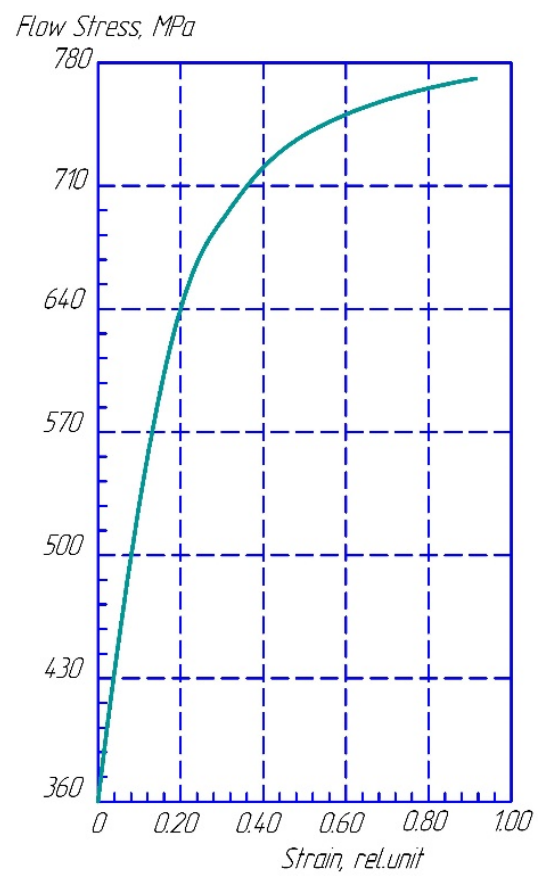

Fig. 4. Diagram "Flow Stress-Strain".

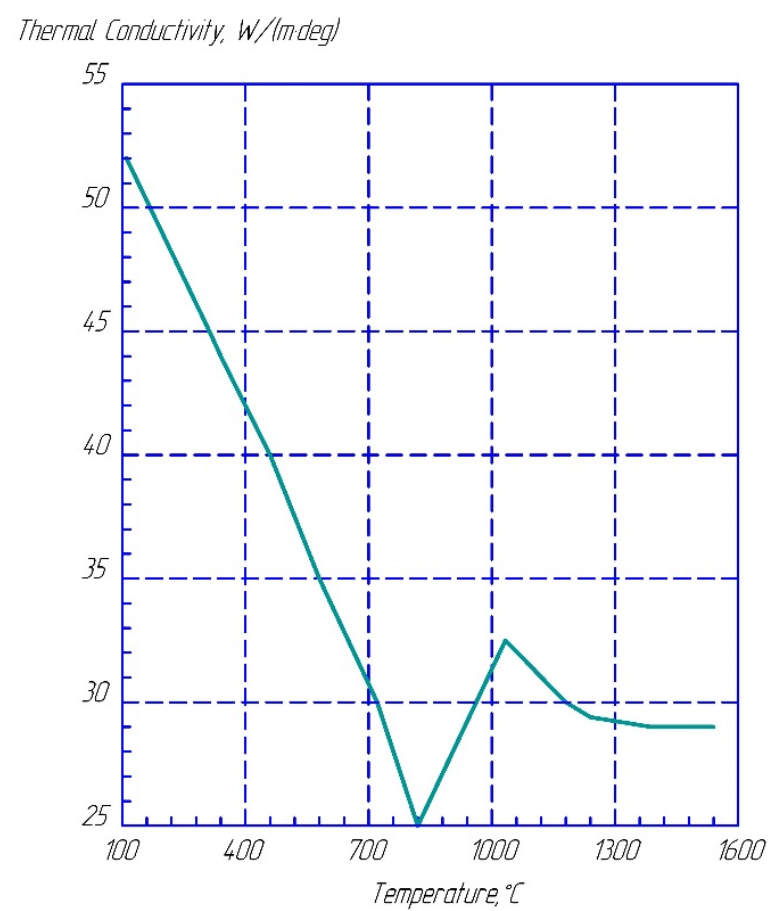

Fig. 5. Thermal conductivity depending on temperature.

Thermal conductivity of material, and its dependence on temperature is shown in Fig. 5, where it is shown that with increasing temperature, thermal conductivity decreases until temperature reaches $800^{\circ} \mathrm{C}$. During further heating thermal conductivity increases until temperature reaches $1000^{\circ} \mathrm{C}$, after this temperature thermal conductivity decreases again. So, treatment is carried out under conditions of maximum thermal conductivity.

Heat capacity of investigated material, which depends on treatment temperature, was determined (Fig. 6). Graph shows that heat capacity of treated steel at temperature of $700^{\circ} \mathrm{C}$ takes maximum values. At treatment temperature of $1000^{\circ} \mathrm{C}$, heat capacity decreases.

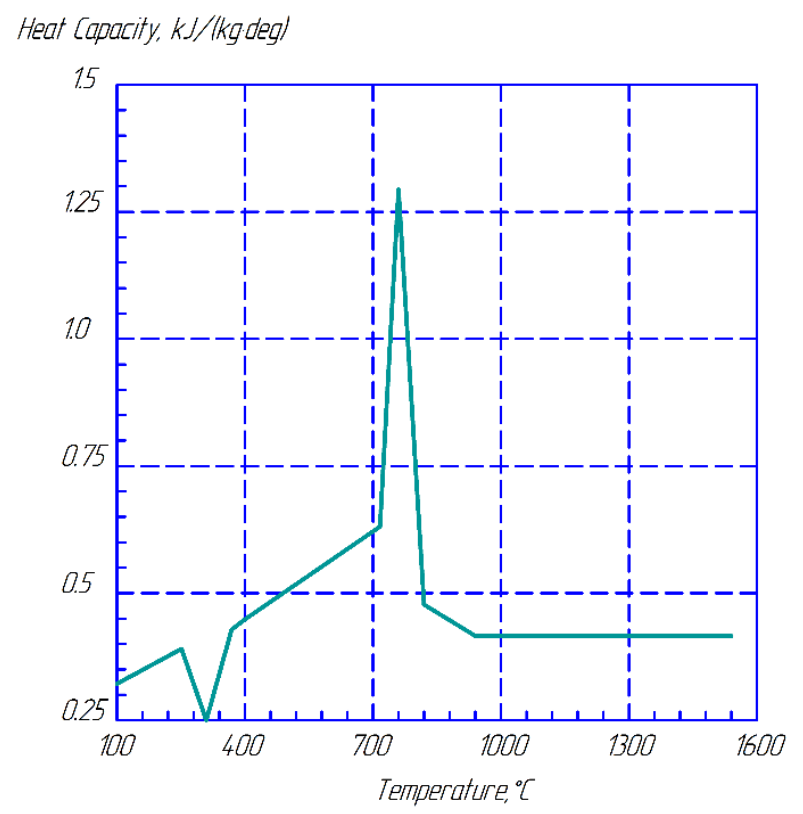

Fig. 6. Dependence of heat capacity of steel on temperature.

Thus, model of hot rolling of thick sheets was constructed to investigate processes occurring in deformation zone.

\section{Results of investigation of energypower parameters of hot rolling of thick sheets}

Investigation of deformation distribution in treated material enabled to identify its displacement during reduction (Fig. 7). Figure shows distance of displacement and its distribution in deformation zone.

Material flow along curvature of coordinate grid can be seen on Fig. 8, which shows that maximum deviation from original location occurred in center of deformation zone with upper layers.

Vector field of metal displacement during deformation was investigated (Fig. 9), which shows metal movement direction during reduction and displacement of grid points. During simulation process, graph of deformation force change in course of time is made, where it can be seen that force increases from zero to $6.68 \mathrm{MPa}$ during first $27 \mathrm{~s}$. After this, force slowly increases to $8.35 \mathrm{MPa}$ and displacement of metal varies from 1.34 to $25.2 \mathrm{~mm}$.

During simulation process, graph of deformation force change in course of time is made, where it can be seen that force increases from zero to $6.68 \mathrm{MPa}$ during first $27 \mathrm{~s}$. 


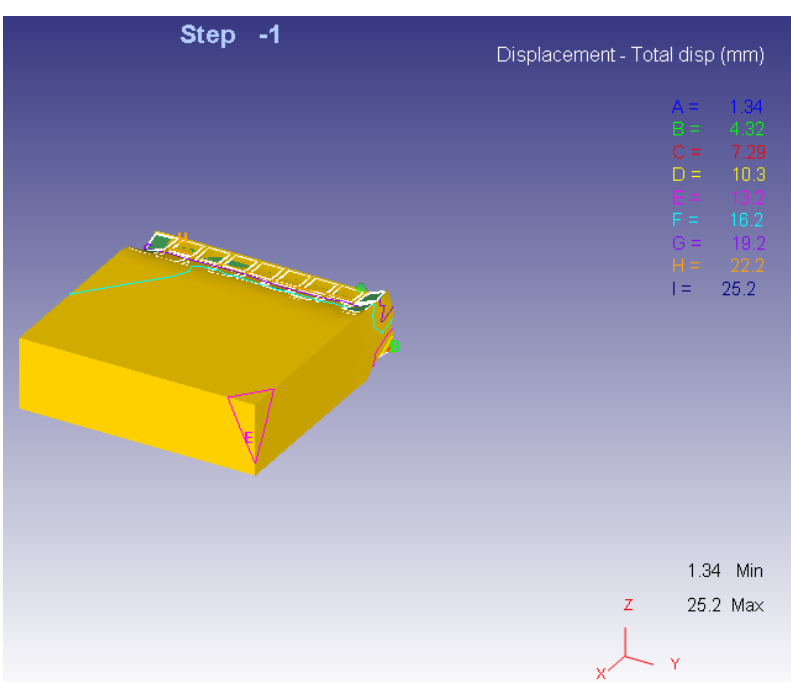

Fig. 7. Metal displacement in deformation zone during reduction.

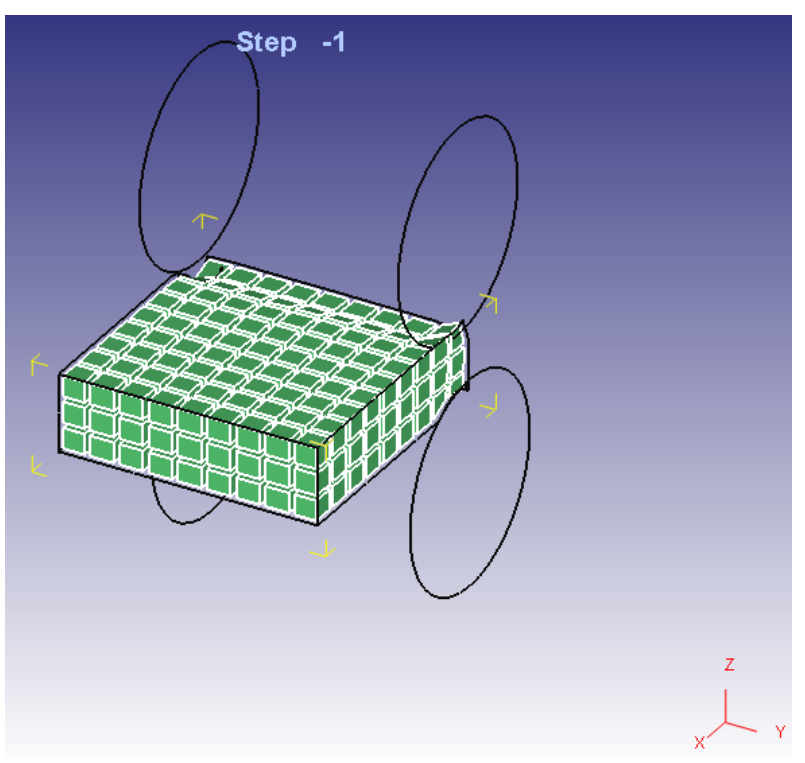

Fig. 8. Coordinate grid of billet.

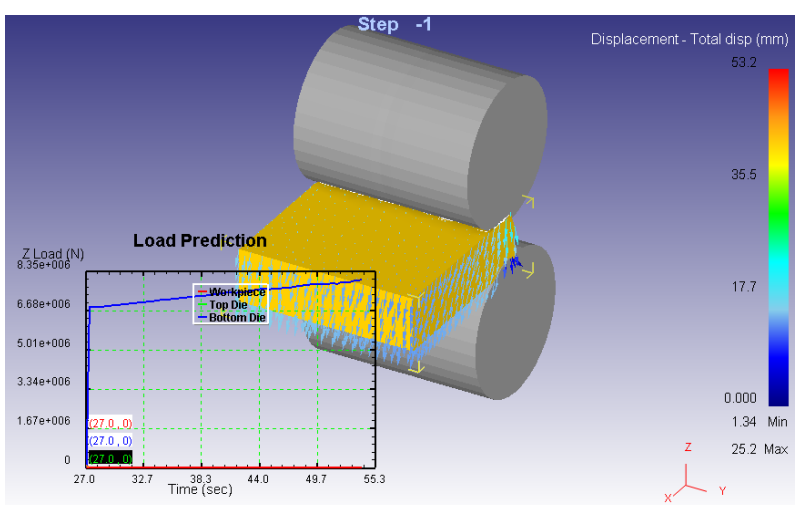

Fig. 9. Vector field of metal displacement during deformation.

After this, force slowly increases to $8.35 \mathrm{MPa}$ and displacement of metal varies from 1.34 to $25.2 \mathrm{~mm}$.

Figure 10 shows graph of change of force applied on roller at initial rolling moment, where it can be seen that force applied on roller varies from 0 to $4.1 \mathrm{MN}$ and displacement fields apply up to $27 \mathrm{~mm}$. Under real conditions for these modes, rolling force reached 4.4 MN [11], which corresponds to high simulation accuracy, where error is $6 \%$.

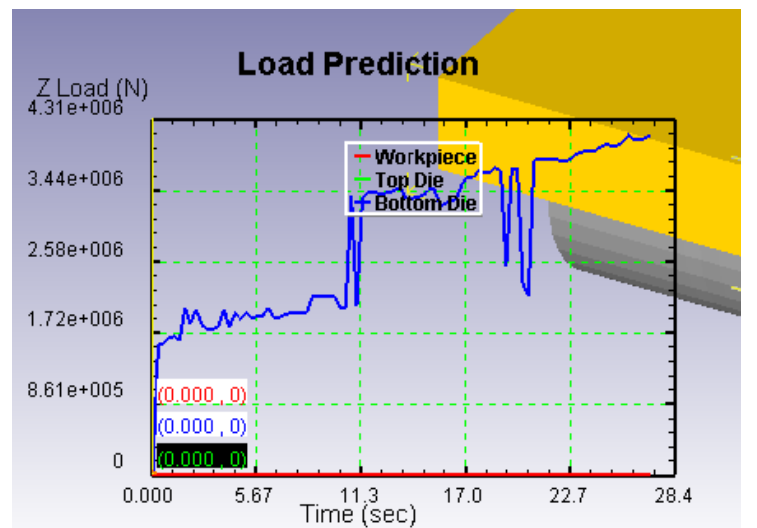

Fig. 10. Change of force applied on roller.

During treatment under pressure, treated material is subjected to non-uniform stress that causes non-uniform plastic deformation. It is determined that both circumferential and normal stress occur during rolling.

Change of stress during deformation was investigated (Fig. 11). It is found out that during hot rolling, large reduction, which reaches more than $10 \mathrm{~mm}$, reduce effect of stress non-uniformity on product quality.

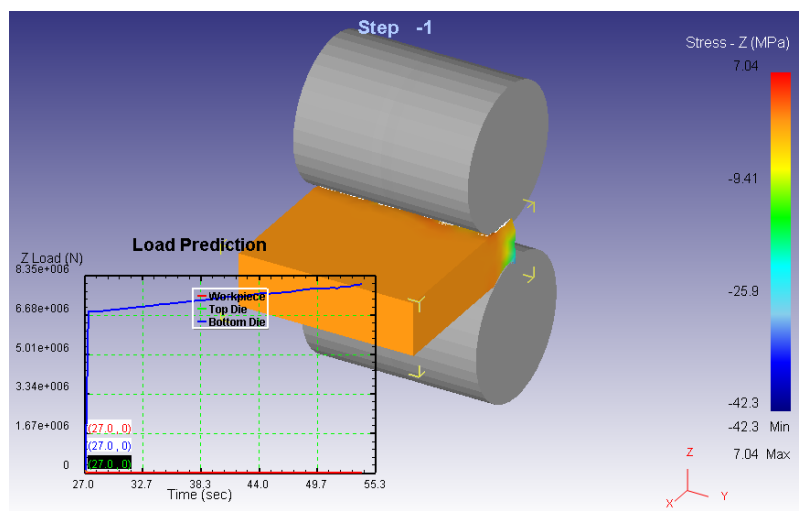

Fig. 11. Change of stress during deformation.

Distribution of acting stress according to its value is shown in Fig. 12, where it is seen that its value in deformation zone reaches $37 \mathrm{MPa}$ and decreases with decreasing reduction value.

\section{Discussion of energypower parameters investigation results and identification of rational reduction modes}

Thus, deformation and energy parameters of hot rolling were investigated by finite element simulation of processes in DEFORM 3D complex. Developed model takes into account direction of metal displacement during rolling, change of force during reduction in deformation zone, distribution of acting stress and its change. Such investigations allowed to develop technological scheme which usage enables to increase accuracy and to improve 
internal structure of metal products at rational energy consumption.

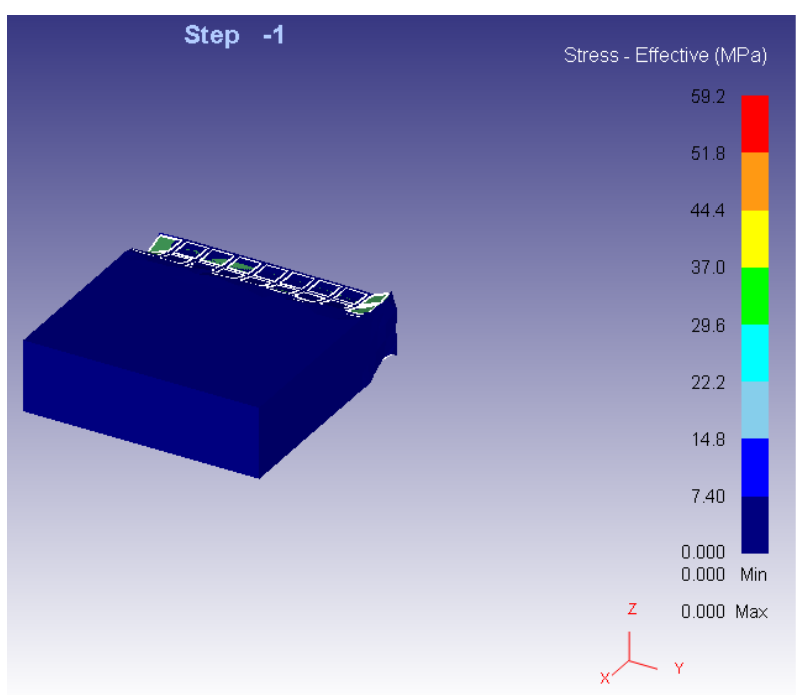

Fig. 12. Distribution of acting stress in deformation zone.

Investigations enabled to identify energy consumption for rolling process depending on reduction modes, what enabled rational treatment modes.

Energy consumption includes kinetic energy of rolled workpiece, potential energy in deformation zone for surface tension formation and metal strengthening, strain energy and energy for metal heating [11].

Kinetic energy of rolled workpiece was determined according to formula [11]:

$$
E_{k}=0,5 \rho b_{1} h_{1} v_{1}^{3},
$$

where $v_{1}-$ roller speed; $b_{1}-$ width of strip after rolling; $\rho$ - steel density, $\rho=6860 \mathrm{~kg} / \mathrm{m}^{3}$.

Potential energy consumption in deformation zone for surface tension formation and metal strengthening are determined according to formula:

$$
E_{p}=2 b_{1} h_{1} v_{1} \sigma_{s t}+V \sigma_{T} / \tau,
$$

where $V$ - deformation zone volume; $\mathrm{m}^{3} ; \sigma_{s t}$ - surface tension; $\tau$-duration of metal being in deformation zone; $\sigma_{T}-$ yield strength.

Strain energy:

$$
A=\sigma_{T}\left(\varepsilon_{h}+\varepsilon_{b}+\varepsilon_{l}\right) h_{1} b_{1} R / \tau,
$$

where $R$ - rollers radius, $\varepsilon_{h} ; \varepsilon_{b} ; \varepsilon_{l}$ - relative deformation of sheet during reduction, broadening and elongation.

Energy consumption per unit of time for heating of rolled products

$$
Q=V \sigma_{T} i / \tau,
$$

where $i$ - heat capacity.

To determine total energy consumption per unit of time, sum of listed items was calculated.

$$
W=E_{k}+E_{p}+A+Q
$$

Investigation results are shown in Table 1.
Table 1. Energy-power parameters of hot rolling process.

\begin{tabular}{|c|c|c|c|c|}
\hline $\begin{array}{c}h_{0}, \\
\mathrm{~mm}\end{array}$ & $\begin{array}{c}h_{1}, \\
\mathrm{~mm}\end{array}$ & $\begin{array}{c}b_{1}, \\
\mathrm{~mm}\end{array}$ & $\begin{array}{c}v_{1}, \\
\mathrm{~m} / \mathrm{s}\end{array}$ & $\begin{array}{c}W, \\
\mathrm{~kJ} / \mathrm{s}\end{array}$ \\
\hline 300 & 255 & 1150 & 5,12 & 878474,2 \\
\hline 500 & 400 & 1200 & 3,2 & 10144297 \\
\hline
\end{tabular}

Such investigations enabled to use rational reduction modes (Table 1) during development of technological process of thick sheets manufacturing by hot rolling, which ensures sustainable development of rolling technologies.

\section{Conclusions}

During execution of investigation on hot rolling process of thick sheets, following results were obtained:

- opportunity to use finite elements analysis for investigation on processes of metal treatment under pressure was analyzed, that enabled execution of investigation on hot rolling process of thick sheets using computer software DEFORM 3D;

- model of hot rolling process that enables to investigate physical and mechanical processes in deformation zone, which occur during metal treatment under pressure was developed;

- deformation force and its distribution in deformation zone were identified; energy consumption and rational reduction modes during hot rolling of thick sheets that enable manufacturing of high-quality products were specified;

- it is suggested to use rolling modes adopted in Table 1 during manufacture of thick sheets to save $6-8 \%$ of energy during plate rolling

\section{References}

1. V.M. Danchenko, V.O. Hrynkevych, O.M. Holovko. The theory of metal treatment by pressure (Porogi, Dnipro, 2008)

2. I.K. Oginskiy, V.N. Danchenko, A. A. Samsonenko, V.V. Boyarkin, Metal deformation processes based on multi-roll calibers (Porogi, Dnipro, 2011)

3. G. Faraji, H. Jafarzadeh, Materials and Manufacturing Processes. Accumulative Torsion Back (ATB) Processing as a New Plastic Deformation Technique. J. Mat. and Mat. Proc. 27(5), 507-511 (2012). doi:10.1080/10426914.2011.593235

4. G.E. Kodjaspirov, A.I. Rudkoy, V.V. Rybin, Advanced Materials Research. Effect of thermomechanical processing on structure and corrosion-mechanical properties of AISI 321 steel. East-Europ. J. of Ent. Tech. 89, 769-772 (2010)

5. B.C. Hwang, H.I. Lee, W.B. Bae, A UBET analysis of the non-axisymmetric combined extrusion process. J. Mater. Process. Technol. 139(1), 547-552 (2003). doi:10.1016/S0924-0136(03)00523-5

6. J. Monaghan, An investigation of plane-strain lateral extrusion to form components having staggered 
branches. J. Mater. Process. Technol. 77, 305-309 (1998)

7. F. Fereshteh-Saniee, B. Daneshzad-Moghaddam, A new CAD system for finisher die design of an axisymmetric forging component with arbitrary profile. J. Mater. Process. Technol. 153-154, 157163 (2004). doi:10.1016/j.jmatprotec.2004.04.201

8. V.N. Danchenko, A.A. Milenin, V.I. Kuzmenko, V.A. Grinkevich, Computer simulation of metal treatment by pressure (System technology, Dnipro, 2005)

9. V.S. Parshin, A.P. Karamyshev, I. I. Nekrasov, The practical guide to DEFORM-3D (UrFU, Ekaterinburg, 2010)

10. DEFORM 3D Version 6.1 (sp1) User's Manual (Scientific Forming Technologies Corporation, Columbus, 2007), https://vdocuments.mx/deform3d-v61-manual.html. Accessed 15 Oct 2015

11. V.A. Chubenko, A.A. Khinotska, Investigation of volume-structural and energy transformations during steel rolling (Chernyavsky, Kryvyi Rih, 2018) 